\title{
Renewable polymeric materials for electronic applications
}

\author{
Han-Sheng Sun ${ }^{1}$, Yu-Cheng Chiu ${ }^{2}$ and Wen-Chang Chen ${ }^{1}$
}

Renewable polymers have attracted extensive research interest as substitutes for fossil fuel-based materials because they are sustainable and biodegradable. With the rapid increase in the applications of electronic devices, the integration of renewable polymers with electronics not only enhances the economic benefit of waste natural resources but also conserves our environment. In this review, an overview of renewable materials used in electronics, including passive components (that is, substrates, photoresists, templates and dispersion agents) and active components (that is, luminescence layers, protontransporting layers and charge-trapping layers), as well as their future perspective is provided. The relationships between chemical structures, their morphologies and the device characteristics will be discussed. It is hoped that this review will stimulate research and generate interest in applications of renewable materials for the electronics industry.

Polymer Journal (2017) 49, 61-73; doi:10.1038/pj.2016.95; published online 19 October 2016

\section{INTRODUCTION}

Synthetic polymers have inspired a broad range of applications because of their design flexibility, strong mechanical strength and solution processability. However, fossil fuel sources are used to prepare synthetic polymers, leading to serious environmental pollution. To address this issue, renewable polymers have received extensive interest over the past decade, which has been driven by their environmentally friendly value as renewable biomaterials and as a sustainable source of materials. ${ }^{1-4}$

An extensive range of renewable materials from animal, plant and bacteria (Figure 1) has been investigated, including naturally occurring polymers such as cellulose, chitin, starch and numerous proteins. These materials comprise lignins, hemicelluloses, suberin, terpenes, steroids, vegetable oils, oligosaccharides, polysaccharides, polyunsaturated fatty acids and lipids. ${ }^{5-34}$ These materials are widely used in diverse fields, including in paper-making, adhesives, coating materials, biomedical application and manufacturing biofuels to name a few. For example, polysaccharides converted from solar energy or carbohydrates converted through organisms are two very attractive renewable materials because of their inexhaustible sources, with a production of $10^{13}$ tons annually. In addition, specific metabolites produced from microorganisms using various biotechnologies (for example, metabolic or genetic engineering) are an important source of feedstock for valuable polymers because the microorganisms digest inexpensive sugar. Polylactic acid (PLA), which is derived from starch or sugarcane via fermentation, has excellent degradation properties and is the world's second largest consumed bioplastic for bio-packaging, surgical sutures and as a substrate for organic electronics. ${ }^{33,35-39}$

More recently, with increasing demands for state-of-the-art electronics, the issue of how to bridge non-petroleum-based materials with the current digital life is being examined carefully. Renewable polymers that possess outstanding biodegradability have eco-friendly processability, and are inexhaustible attract considerable interest with regard to their integration with electronics. Such integration would both enhance the economic benefit of waste natural resources and conserve the environment. However, incorporating renewable polymers into active electronics with a high-performance signal output is a significant challenge. Indeed, the poor electroactivity of renewable polymers has limited their widespread application. Nevertheless, persistent environmental concerns have greatly encouraged their use in electronics as substrates, templates and dispersants for developing biodegradable organic electronics or nanopatterning techniques, as shown in Figure 1. More recently, the incorporation of functional groups into renewable polymers was found to actively affect or control the output electrical signals of organic electronics, providing a novel strategy for the design of electronics integrated with biomaterials. However, a comprehensive review of renewable materials for electronic devices is lacking.

Thus, the objective of this review is to provide an overview of renewable polymers used in electronics and their future perspective. We focus on the applications of passive and active electronic components using renewable materials, with particular emphasis on the relationships between their chemical structures, morphologies and

${ }^{1}$ Department of Chemical Engineering, National Taiwan University, Taipei, Taiwan and ${ }^{2}$ Department of Chemical Engineering and Materials Science, Yuan Ze University, Taoyuan, Taiwan

Correspondence: Professor Y-C Chiu Department of Chemical Engineering and Materials Science, Yuan Ze University, Taoyuan 320, Taiwan.

E-mail: yuchengchiu@saturn.yzu.edu.tw

or Professor Wen-Chang Chen, Department of Chemical Engineering, National Taiwan University, No. 1., Sec. 4, Roosevelt Road, Taipei 106, Taiwan.

E-mail: chenwc@ntu.edu.tw

Received 29 June 2016; revised 18 August 2016; accepted 19 August 2016; published online 19 October 2016 


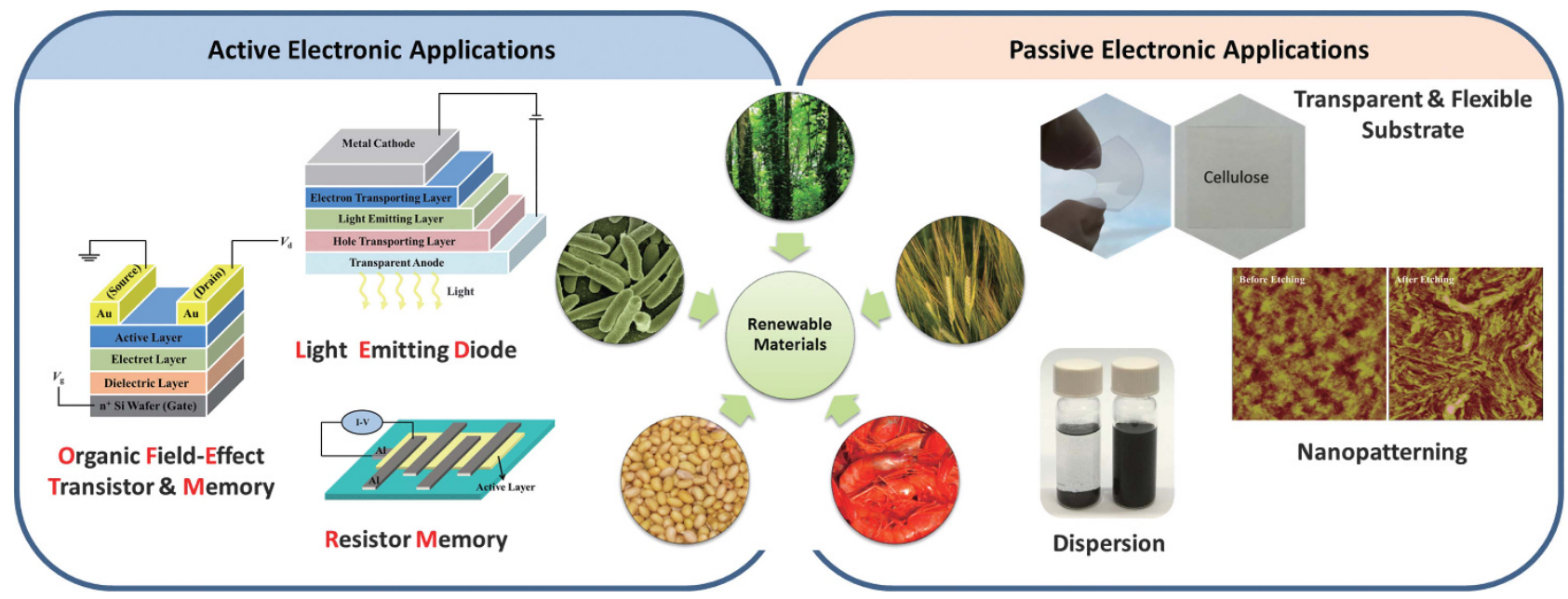

Figure 1 Schematic of renewable polymers for electronic applications.
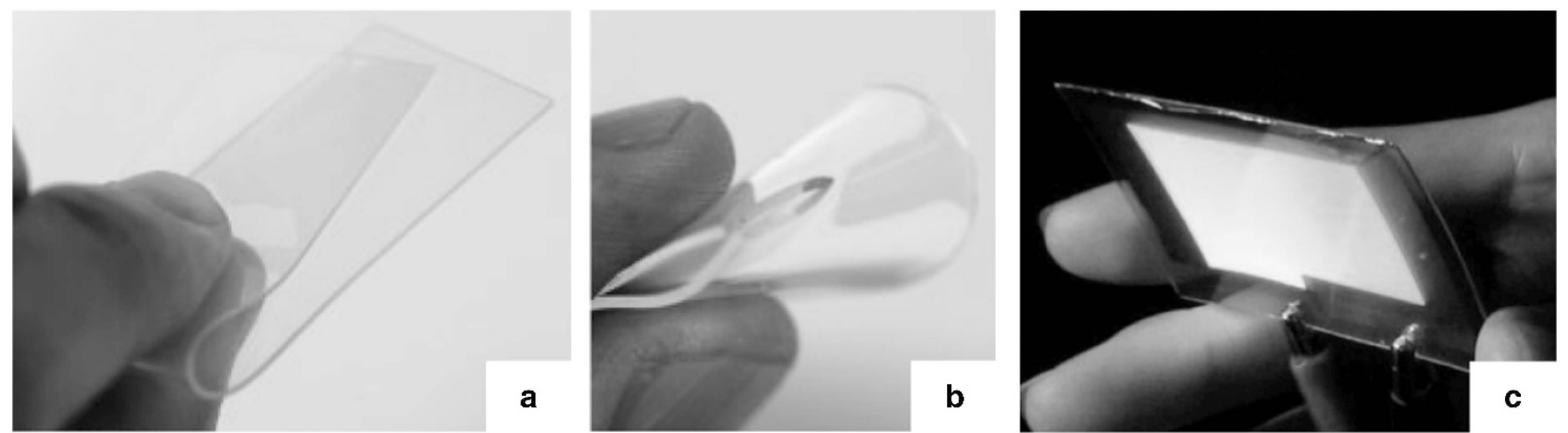

Figure 2 (a) Foldable transparent BC composite substrate, (b) brittle acrylic resin with the same thickness of a bacterial cellulose (BC) composite substrate and (c) light-emitting diode fabricated on a BC composite substrate. Reprinted with permission from ref. 42. Copyright 2008, Wiley-VCH. A full color version of this figure is available at Polymer Journal online.

device characteristics. First, we will discuss renewable polymers used in passive applications, such as transparent and flexible substrates for electronics, green photoresist, templates for nanopatterning and dispersing agents for carbon-based electronic devices. Next, we will discuss renewable polymers for active components of electronic applications, including light-emitting layers in light-emitting diodes, proton-transporting layers, electron-trapping layers, and high- $k$ dielectrics and active charge-trapping layers in electrical memory devices. It is anticipated that renewable polymers have a bright future in the electronics industry.

\section{RENEWABLE INSULATING POLYMERS FOR ELECTRONIC APPLICATIONS}

Substrates

Currently, the development of a smaller, lighter and flexible display is a continuing trend for handheld soft devices. To meet this demand, polymeric substrates are one of the potential candidates to replace glass, but most plastic materials have a large coefficient of thermal expansion (CTE), on the order of 50-200 p.p.m. $\mathrm{K}^{-1}$. As a result, the functional materials deposited onto the plastic substrates would be destroyed from thermal processes because of the mismatch between the CTEs from different materials. However, Nogi reported cellulose nanofibers with CTE values as low as 0.1 p.p.m. $\mathrm{K}^{-1}$ along the axial direction. ${ }^{40}$ In addition, bacterial cellulose (BC) has been used as a reinforcement to enhance the strength and decrease the CTE for transparent plastics. ${ }^{41}$ Thus, Nogi and co-workers discovered a foldable transparent BC composite film with a low CTE (of 4 p.p.m. $\mathrm{K}^{-1}$ ) and utilized it as a substrate in an organic light emitting diodes device (Figure 2). Compared with pure acrylic resin, the BC composites showed excellent optical transmittance (of $81.3 \%$ ) at a wavelength of $600 \mathrm{~nm}$, enhanced yield strain that varied from 5.0 to $14.2 \%$, and a reduced planar thermal expansion of $0.05 \%$ in the range $20-150^{\circ} \mathrm{C}$, which was much better than a previously reported blend system. ${ }^{42}$

Apart from BC composites, cellulose triacetate films prepared from ramie fiber have also been utilized as protective films for polarizing plates in liquid crystal displays. ${ }^{43}$ For instance, Huang et al. ${ }^{44}$ reported a highly transparent and flexible nanopaper transistor fabricated on nanofibrillated cellulose as the substrate. ${ }^{35}$ The fabricated transistor device using NTCDI-F15 as the semiconducting layer exhibited high transparency up to $83.5 \%, n$-type mobility of $4.3 \times 10^{-3} \mathrm{~cm}^{2} \mathrm{~V}^{-1} \mathrm{~s}^{-1}$, an on/off current ratio of 200 , and only a $10 \%$ decrease in mobility after bending or folding.

\section{Green photoresists}

Photolithography is used in the semiconductor industry to create integrated circuit patterns on wafers. In this process, the photoresist containing a light-sensitive chemical undergoes photo-polymerization 


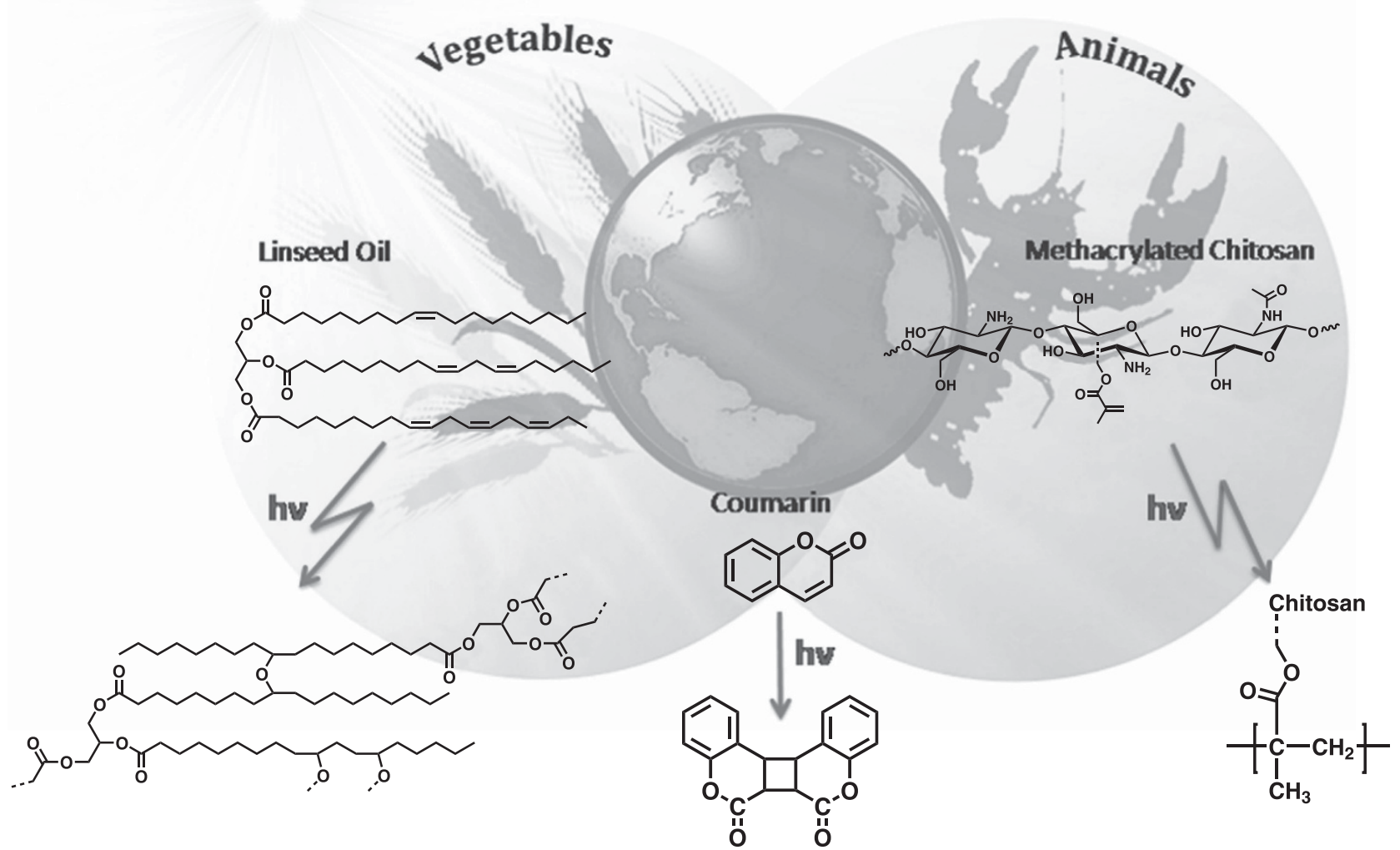

Figure 3 Schematic illustration of green photoresists produced from renewable materials. Reprinted with permission from ref. 47. Copyright 2013, Elsevier. A full color version of this figure is available at Polymer Journal online.

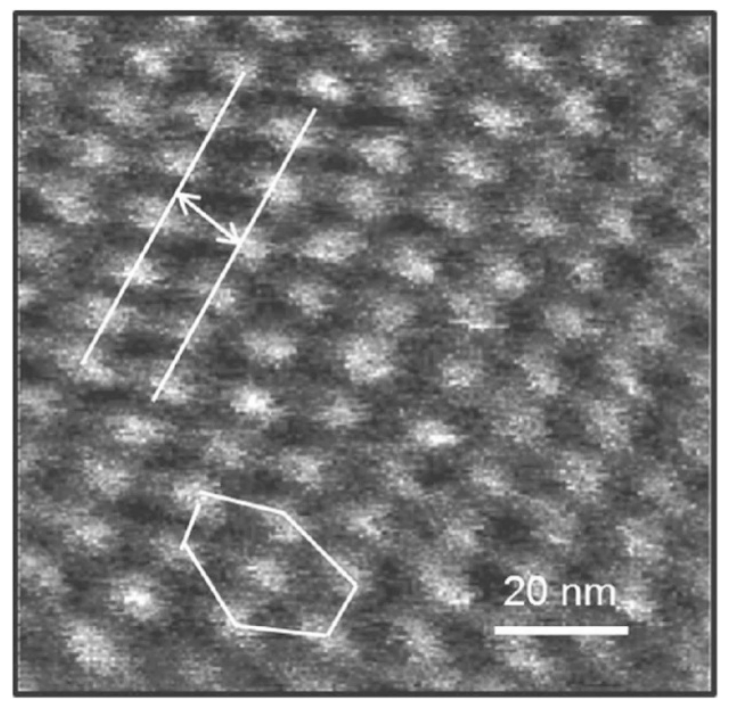

Figure 4 Atomic force microscopy (AFM) phase image of oligosaccharide/siliconcontaining hybrid block copolymers ( $\mathrm{MH}-b$-PTMSS 26 ) after solvent annealing. The row spacing between the features shown in this image is $11.4 \mathrm{~nm}$. Reprinted with permission from ref. 51. Copyright 2012, American Chemical Society. A full color version of this figure is available at Polymer Journal online. upon exposure to ultraviolet (UV) light and transfers the desired pattern onto the substrate from a photomask. The photosensitizer, resin and solvent used in the photoresist include epoxy-based polymers, polyisoprene rubbers, methacrylic acid, methyl methacrylate and vinyl ethers. ${ }^{45,46}$ However, these materials are made from petrochemical processes and thus require the photoresists to be derived from biomass. The monomers that are typically produced from biosourced raw materials include acrylic acid, epichlorohydrin and acrylonitrile. Recently, many renewable molecules from plants and animals have been developed as photosensitive materials. Three different classifications of these materials are shown in Figure 3. The first category contains renewable raw precursors such as lipids, glycerol derivatives, unsaturated oils, (meth)acrylated oils, epoxidized oils, polysaccharide derivatives (including natural acids, polyols and furan derivatives) and functionalized polysaccharides with photocrosslinkable moieties. These precursors can form crosslinking networks through addition reactions with unsaturated double bonds, ring-opening of epoxy groups and acrylate coupling of fatty chains. The second category of naturally derived photosensitive components uses functionalized renewable molecules for UV-cured materials. For example, sugars, amino acids or polypeptides with functionalized modifications can be easily crosslinked by photo-polymerization or coupling reactions. In this case, vinyl, allyl, azido and thiol functional 


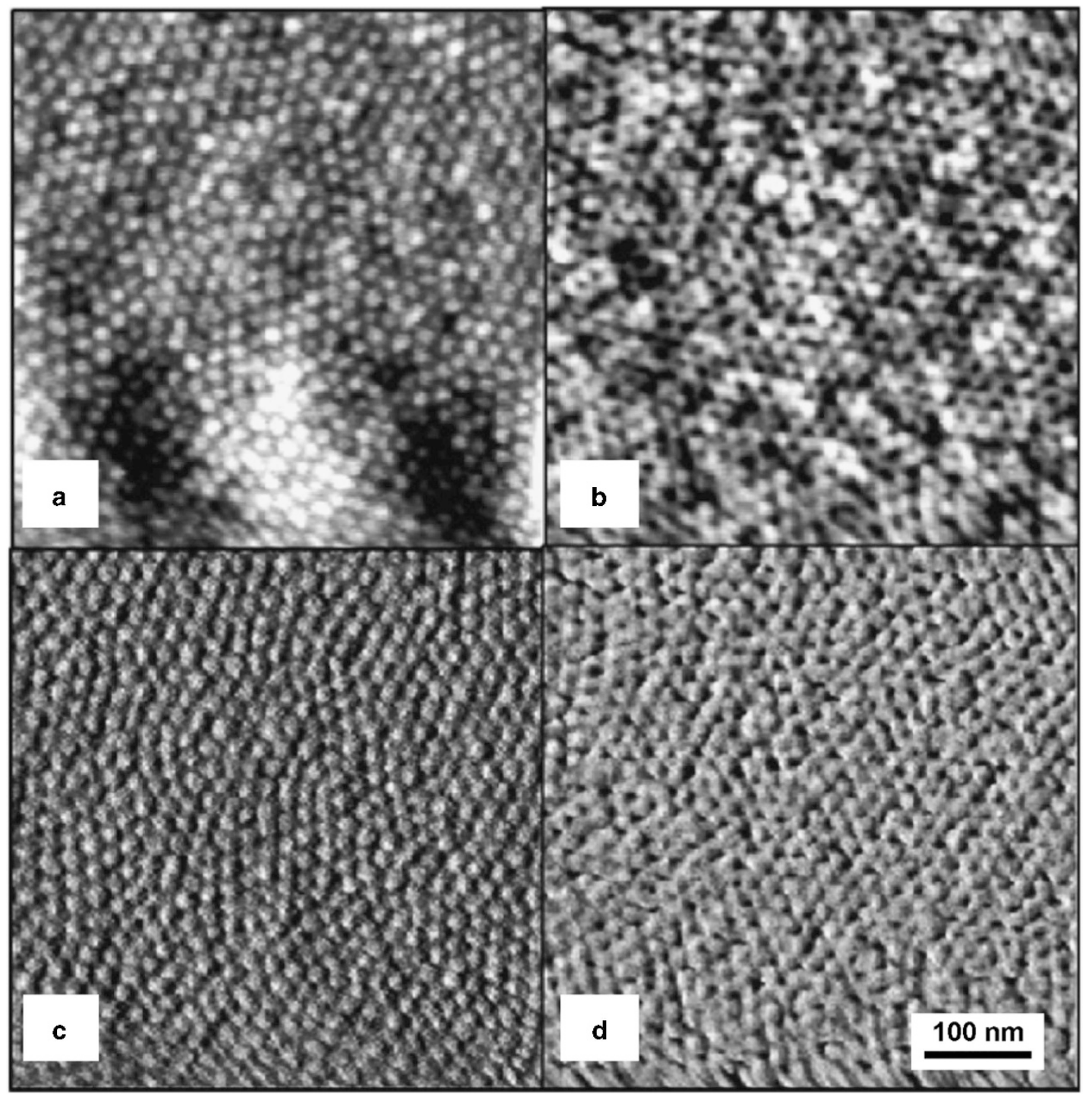

Figure 5 Atomic force microscopy (AFM) topography of a PTMSS ${ }_{5.5}-b$-PLA 3.7 film with a thickness of $19 \mathrm{~nm}$. (a) after $4 \mathrm{~h}$ solvent annealing under cyclohexane vapor; and (b) after $\mathrm{O}_{2}$ plasma reactive ion etching from a. The corresponding AFM phase images. (c) after $4 \mathrm{~h}$ solvent annealing under cyclohexane vapor; and (d) after $\mathrm{O}_{2}$ plasma reactive ion etching from c. The feature size after etching is $\sim 8.8 \mathrm{~nm}$. Reprinted with permission from ref. 52 . Copyright 2012, American Chemical Society. A full color version of this figure is available at Polymer Journal online.

groups are generally utilized. Photoreactive biosourced molecules such as cinnamate, coumarin and furan derivatives constitute the third type of naturally derived photosensitive compounds. These photoresponsive molecules can be $(2 \pi+2 \pi)$ dimerized under UV irradiation and are usually grafted onto polymers as photocrosslinking moieties. ${ }^{47}$

\footnotetext{
Templates

Templates for nanolithography. The aforementioned nanopatterns obtained by photolithography are known as the top-down approach, in which the optical immersion technology (using a wavelength of $193 \mathrm{~nm}$ ) has reached the diffraction limit, making it extremely difficult to scale below dimensions of $22 \mathrm{~nm}$. Currently, several alternative methods have been proposed to overcome this predicament, including nano-imprint lithography, interference lithography, extreme UV lithography and directed self-assembly of block copolymers. ${ }^{45,48,49}$ Among these strategies, the bottom-up approach using block copolymers has been regarded to be a promising route for
}

manufacturing nanopatterns as both their self-assembled feature sizes and the orientation of their periodic arrays can be easily controlled. The fabrication process consists of spin coating on a block copolymer solution, annealing and etching by selectively removing one block of the self-assembled template to obtain the desired nanopattern. On the basis of Flory-Huggins theory, if the $\chi$-value can be effectively increased, a reduced size of the self-assembled domain can be obtained. One effective approach to increase the $\chi$-value is to incorporate a natural polymer block with a synthetic block polymer to minimize the self-assembled feature sizes. ${ }^{50}$ In this regard, Cushen et al. ${ }^{51}$ took advantage of the extremely strong incompatibility between sugar moieties and poly(trimethylsilylstyrene) blocks to generate block copolymers. The natural (oligosaccharide)-synthetic hybrid block copolymers exhibited features exceeding $5 \mathrm{~nm}$ after solvent annealing (Figure 4).

A similar strategy of using renewable materials to create a stronger separation within block copolymers was also successfully demonstrated using PLA as the hydrophilic block. PLA produced from 
P3HT-b-PLLA

a

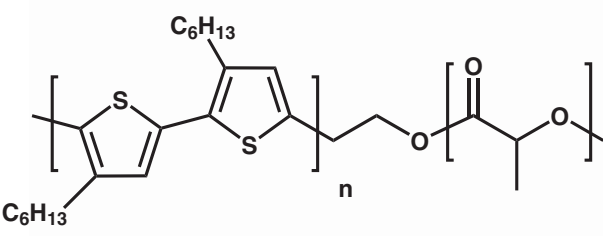

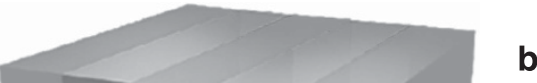

b
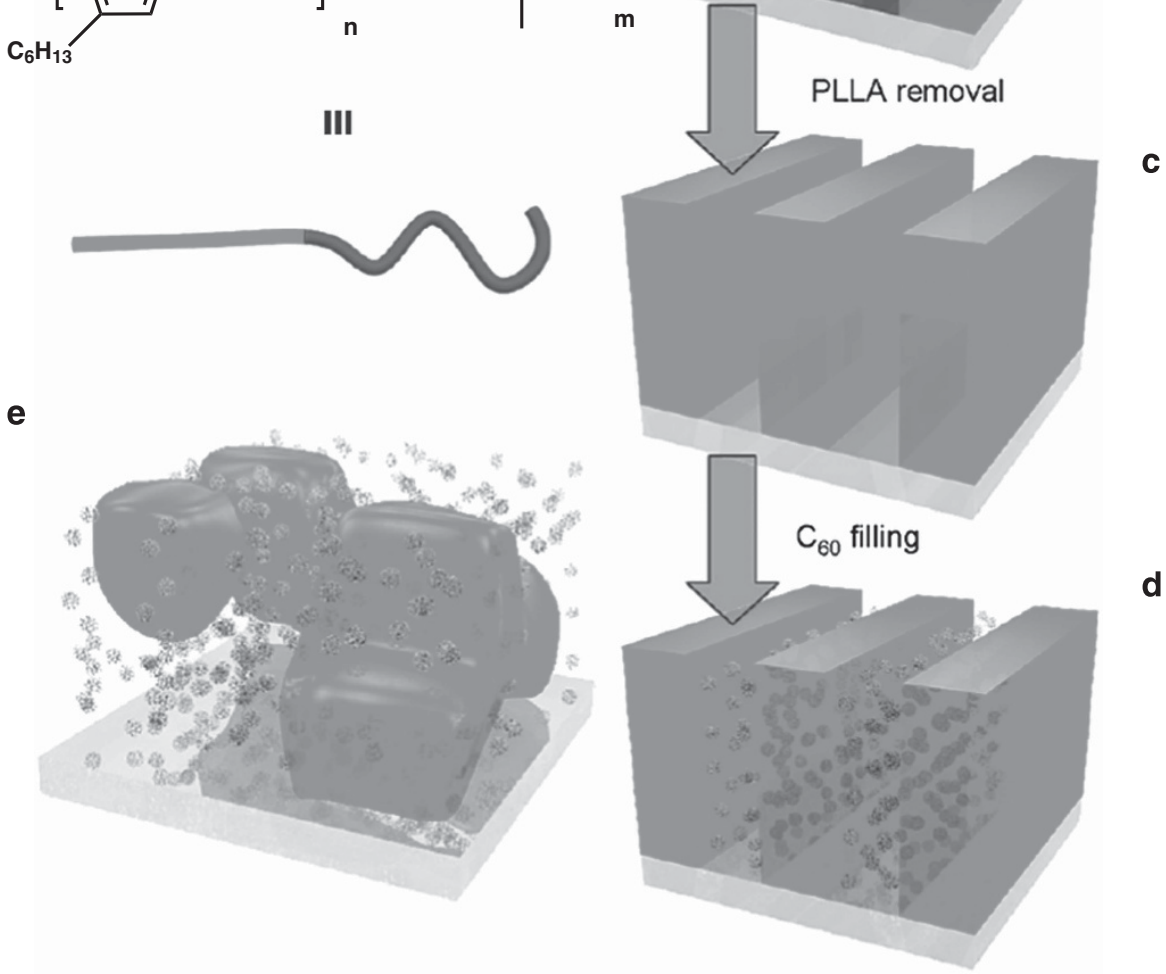

Figure 6 A schematic of the fabrication of a $\mathrm{P} 3 \mathrm{HT} / \mathrm{PC}_{60} \mathrm{BM}$ polymer solar cell with an ordered heterojunction configuration. (a) chemical structure of the poly (3-hexylthiophene) (P3HT)-b-PLLA diblock copolymer. (b) Ordered lamellar morphology of self-assembled P3HT-b-PLLA oriented perpendicular to the substrate. (c) Ordered P3HT nanodomains obtained after removal of the PLLA blocks. (d) Ordered nanomorphology of the P3HT domains, each of them separated by $\mathrm{C}_{60}$ acceptor domains. (e) Morphology of simply blending P3HT homopolymers with $\mathrm{C}_{60}$ acceptors. Reprinted with permission from ref. 56. Copyright 2009, American Chemical Society. A full color version of this figure is available at Polymer Journal online.

cellulose or starch has been widely used in templates because its ester bond linkages can be degraded by bacteria, enzymes and hydrolysis. For this reason, PLA can be used as a removable template for specific purposes. For example, poly(dimethylsiloxane)-block-poly(lactide) $(\text { PDMS- } b \text {-PLA })^{52-55}$ possesses a self-assembled structure with $d$-spacing down to sub-10 nm levels following $\mathrm{O}_{2}$ plasma reactive ion etching (Figure 5). Such small patterns achieved by natural polymers could be potentially used to fabricate the next generation of high-density integrated circuits.

Templates for organic solar cells. For solar cells, an efficient carrier separation at the interfacial space between the donor and acceptor moieties in the active layer is a critical factor that enhances power conversion efficiency. As noted, PLA can be used as a template for nanopatterning and the morphology of the active layer can be controlled using a block copolymer template. Botiz et al. ${ }^{56}$ reported the enhancement of the donor/acceptor interface using poly(3-hexylthiophene) (P3HT)-b-PLLA. P3HT- $b$-PLLA was first annealed to form a lamellar structure with a periodicity of $\sim 8 \mathrm{~nm}$. The PLLA domain was then removed using a $\mathrm{NaOH}$ solution, followed by filling an acceptor into the exposed empty spaces, as shown in Figure 6. The above approach presents a useful strategy for using biomaterials as etching blocks to prepare new donor-acceptor ordered nanoscale morphologies, and it has been considered to potentially improve the performance of organic photovoltaics.

Templates for fabricating nanostructures. The optical, electronic and magnetic properties of metals are tuned effectively by nanostructured morphological designs. Nanostructured gold $(\mathrm{Au})$ has been extensively researched because of its unique chemical and physical characteristics, including catalytic activity, strong light scattering, surface plasmon resonance, ${ }^{57}$ Raman scattering enhancement, and photoluminescence enhancement or quenching. ${ }^{58}$ However, it remains a challenge to control the surface plasmon resonance effect in Au-based materials because it is difficult to assemble large-area continuous films and large-size bulk materials. ${ }^{59,60}$ The gyroid is a continuous and triply periodic cubic morphology, whereas its surface possesses a constant mean zero curvature and is periodic in all three principal spatial directions. ${ }^{61}$ Hsueh et al. ${ }^{60}$ reported a novel route to fabricate well-defined nanostructures and continuous thin films of Au through the templated synthesis of self-assembly block copolymers containing PLLA as the removable moiety (Figure 7). The nanoporous template 


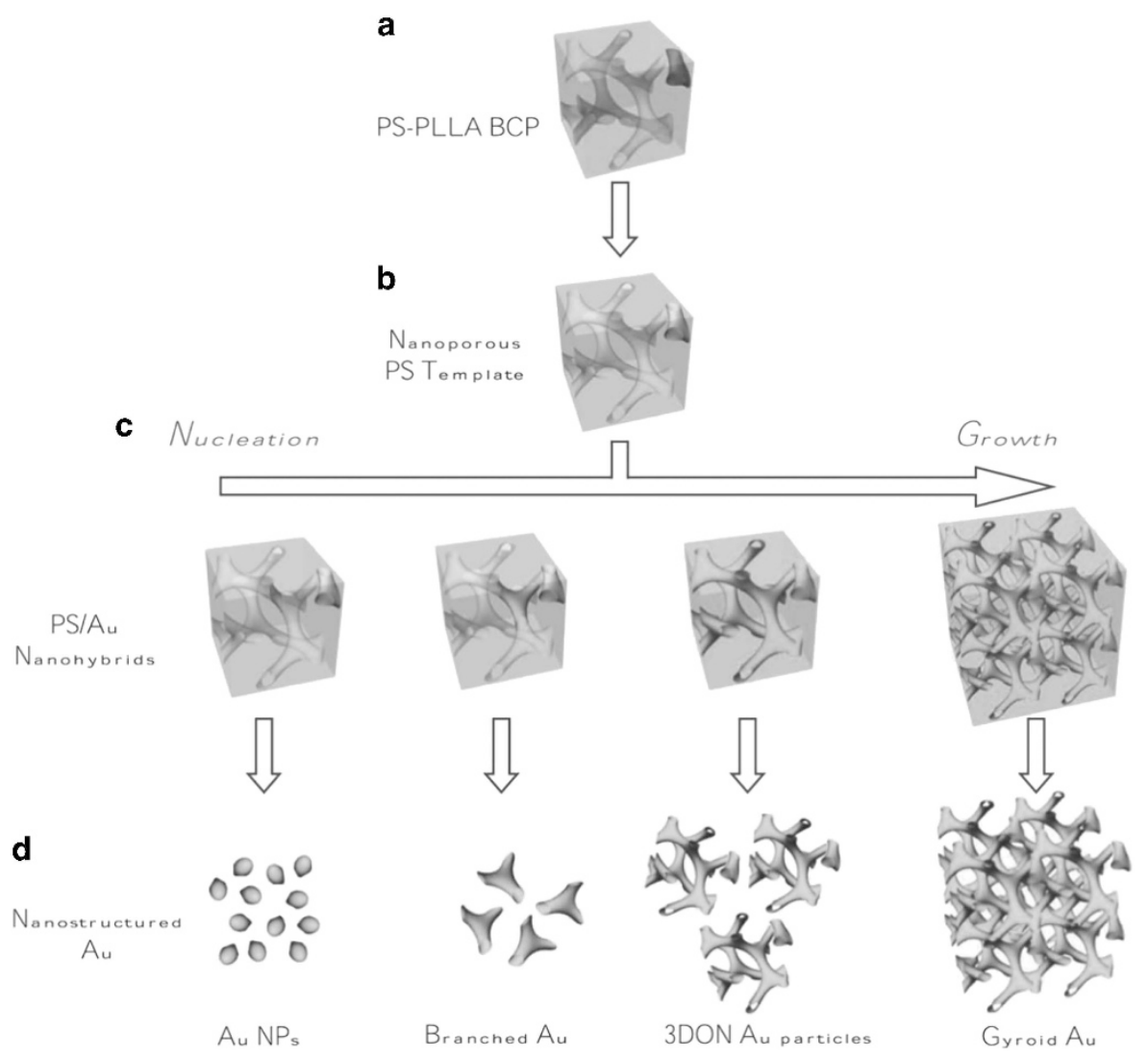

Figure 7 Schematic of the fabrication of well-defined nanostructured Au from a block copolymer template. (a) PS- $b$-PLLA double gyroid phase. (b) Gyroid-like PS nanoporous template. (c) PS/Au nanohybrids from a seeding growth approach. (d) Nanostructured Au after removal of the PS template. Reproduced with permission from ref. 60. Copyright 2013, Wiley-VCH. A full color version of this figure is available at Polymer Journal online.

with the gyroid nanochannels was prepared by self-assembled block copolymers (PS- $b$-PLLA) followed by hydrolysis of the PLLA blocks. Then, a wide range of $\mathrm{Au}$ nanostructures that exhibited surface plasmon resonance were synthesized from the PS nanoporous template using the seeding growth approach, such as Au nanoparticles, branched $\mathrm{Au}$, three-dimensionally ordered nanoporous $\mathrm{Au}$ and gyroid $\mathrm{Au}$, which can be applied to catalysts, photonic crystals, sensors, optoelectronics and Raman scattering enhancement in biomedical applications.

\section{Dispersion agent for carbon materials}

Carbon materials, such as carbon nanotubes and graphene, have been investigated widely in electronic device applications because of their optimal high carrier mobility, large surface-to-volume ratio, outstanding robustness and versatile chemistry. ${ }^{62}$ However, the poor solubility of pristine carbon materials in any solvent limits their widespread use. Many studies of the dispersion of carbon materials have been reported, and carbohydrates are one type of dispersant that could be effective in this regard. Modified mono- or oligosaccharides make it possible to disperse or dissolve carbon materials in aqueous systems and enhance biocompatibility. In this approach, it is common to functionalize carbon materials with carboxylic acid groups and couple them with sugar moieties. Another approach is through non-covalent wrapping with specific intermolecular interactions; for example, carbohydrate conjugates with pyrene or porphyrin groups, glycopolymers, glycolipids and cyclodextrins have all been explored. ${ }^{62-64}$ Sudibya et al. ${ }^{65}$ reported the non-covalent functionalization of single-walled carbon nanotubes with bioactive sugars for nanoelectronic biosensors for the rapid detection of biomolecules. As shown in Figure 8, GlcNAc-functionalized single-walled carbon nanotube nets provide a normal growth and adhesion surface for PC12 cells and are able to detect dynamic biomolecular release from PC12. Therefore, renewable carbohydrate materials represent a promising strategy to disperse CNTs for use in the fabrication of transistors or sensors.

\section{ACTIVE ELECTRONIC COMPONENT APPLICATIONS}

Organic electronics have received widespread attention because of their ideal solution processability, mechanical flexibility, light weight and low cost. A variety of petroleum-based electroactive materials for use as the active layer have been explored. With increasing environmental awareness, renewable materials used in electronics are used not only for the aforementioned passive electronic components but also for the active components. However, the relatively poor insulating property of renewable materials is an extremely challenging issue and limits their application as the active layer in electronic devices. Very recently, the ability to affect the output signals in renewable materials by utilizing an abundance of functional groups, including hydroxyl and acidic groups, has been explored.

\section{Luminescent layers in light-emitting diodes}

Organic light-emitting diodes are emissive electroluminescent devices that are widely used in the digital display industry to fabricate television screens, computer monitors and mobile phones. Usually, the substrates, electrodes, electron-transporting layers, hole-transporting layers and light-emitting layers in common organic light emitting 

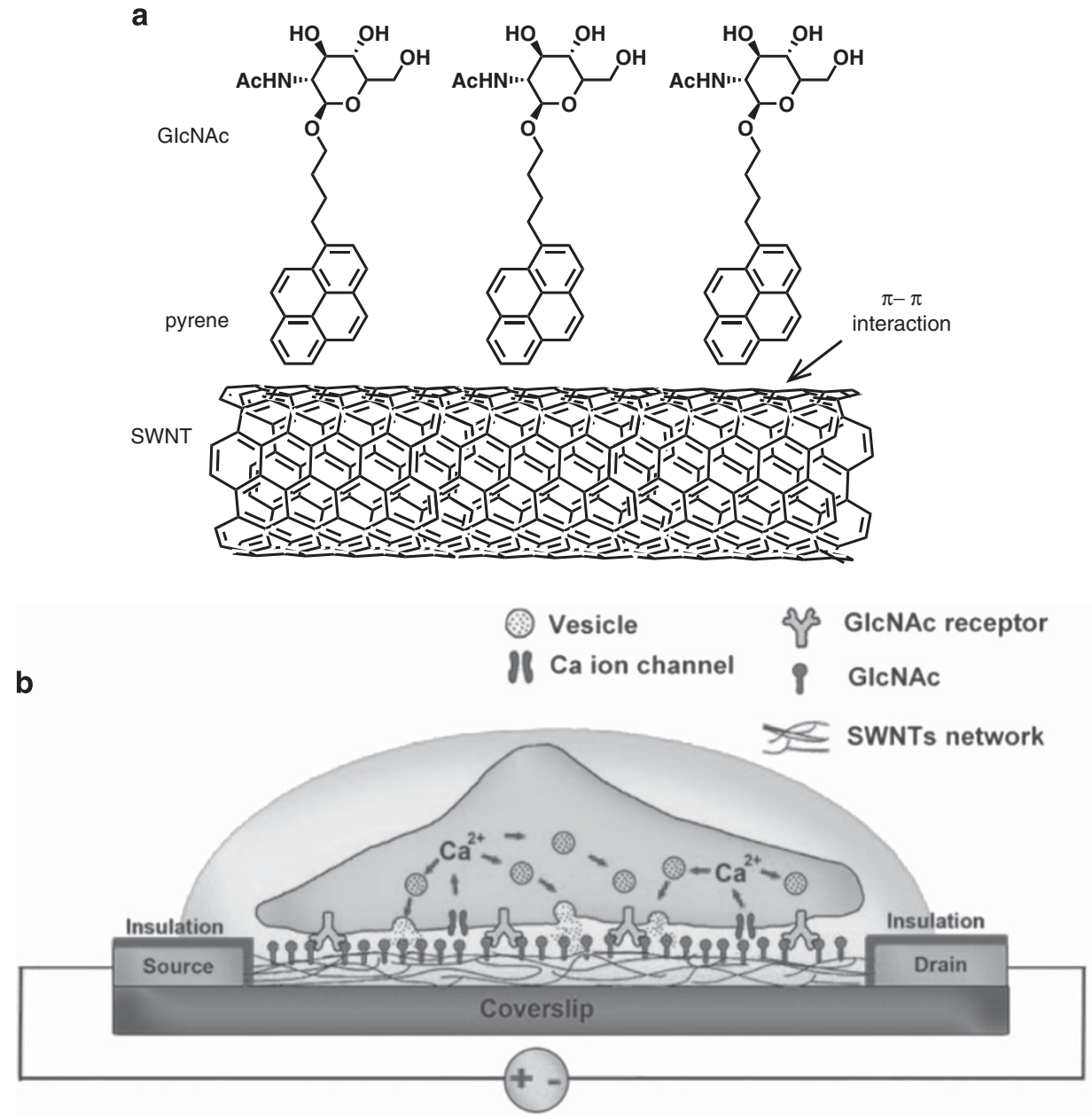

Figure 8 (a) Illustration of GlcNAc-pyrene functionalization of single-walled carbon nanotubes (SWCNTs) and (b) triggered exocytosis and SWNT-net detection. Reproduced with permission from ref. 65. Copyright 2009, Wiley-VCH. A full color version of this figure is available at Polymer Journal online.

a
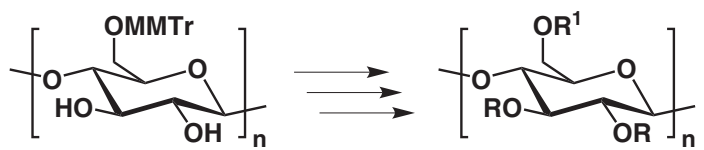

$\mathrm{R}=\mathrm{BCz}, \mathrm{Me}, \mathrm{R}^{1}=\mathrm{Me}$

$R=M e, R^{1}=B C z$

b
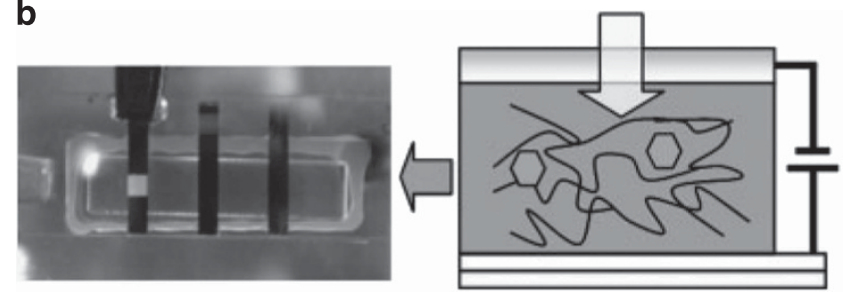

Figure 9 (a) Chemical structures and (b) fabricated organic light-emitting diode devices of fluorescent cellulose derivatives. Reproduced with permission from ref. 66. Copyright 2007, Wiley-VCH.

diodes configurations are made of petroleum-based products rather than materials derived from renewable sources. However, Karakawa et al. ${ }^{66}$ reported the first synthesis of fluorescent polymers based on cellulose modified with alkyl carbazole derivatives (Figure 9). The ionization potentials of the cellulose derivatives are $\sim 5.8 \mathrm{eV}$. The derivatives exhibit UV-blue emissions at $350-450 \mathrm{~nm}$, which is attributed to the carbazole groups and similar to emissions from neat poly( $N$-vinylcarbazole). Furthermore, the cellulose materials that were integrated into an organic light-emitting diode showed a high current density and a low turn-on voltage of $6.5 \mathrm{~V}$ for $0.1 \mathrm{~cd} \mathrm{~m}^{-2}$ light emission. ${ }^{66}$ These results indicate that carbazole-functionalized cellulose has the potential to serve as the hole-transporting materials in organic light-emitting diodes. This study, which highlighted the utility of modifying the functional groups in cellulose with electroactive moieties, pioneered the early stages for developing renewable materials for electronic device applications.

\section{Active layer in resistive memory}

Resistive memory devices with metal-insulator-metal structures are composed of an insulating or resistive material sandwiched between two electron-conductive electrodes. A wide range of organic and inorganic resistive materials has been studied; however, carbohydrate polymers have not been investigated because of their lack of conjugated moieties to transport or trap carriers. To improve the electrical properties of carbohydrate polymers, incorporating electroactive species into the materials has been shown to be an effective approach. In particular, Karakawa et al. ${ }^{67}$ reported that carbazole-substituted cellulose could be used to fabricate resistive 
a

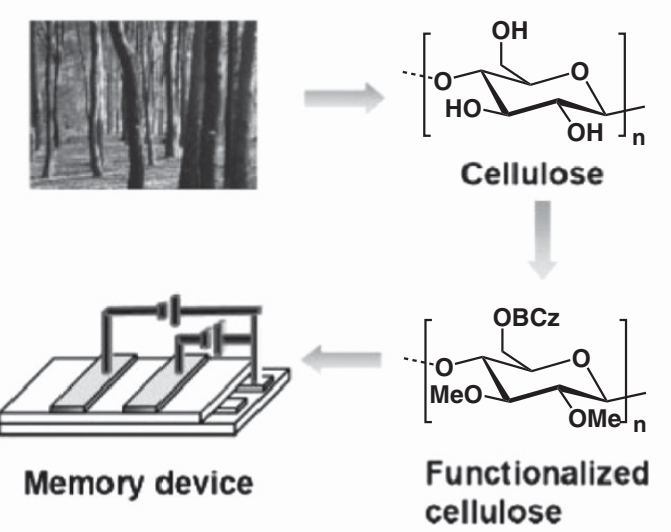

b

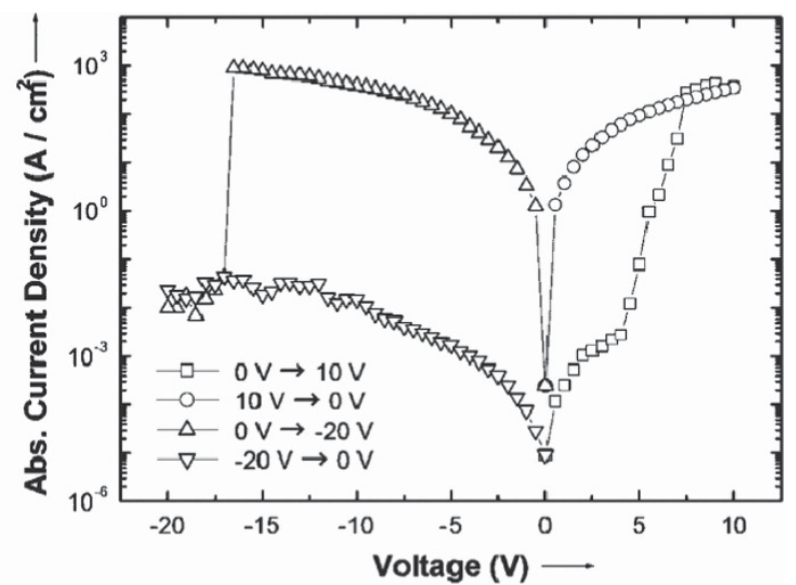

Figure 10 (a) Organic memory device-based carbazole-functionalized cellulose and (b) its current density-voltage characteristics. Reproduced with permission from ref. 67. Copyright 2007, Wiley-VCH.

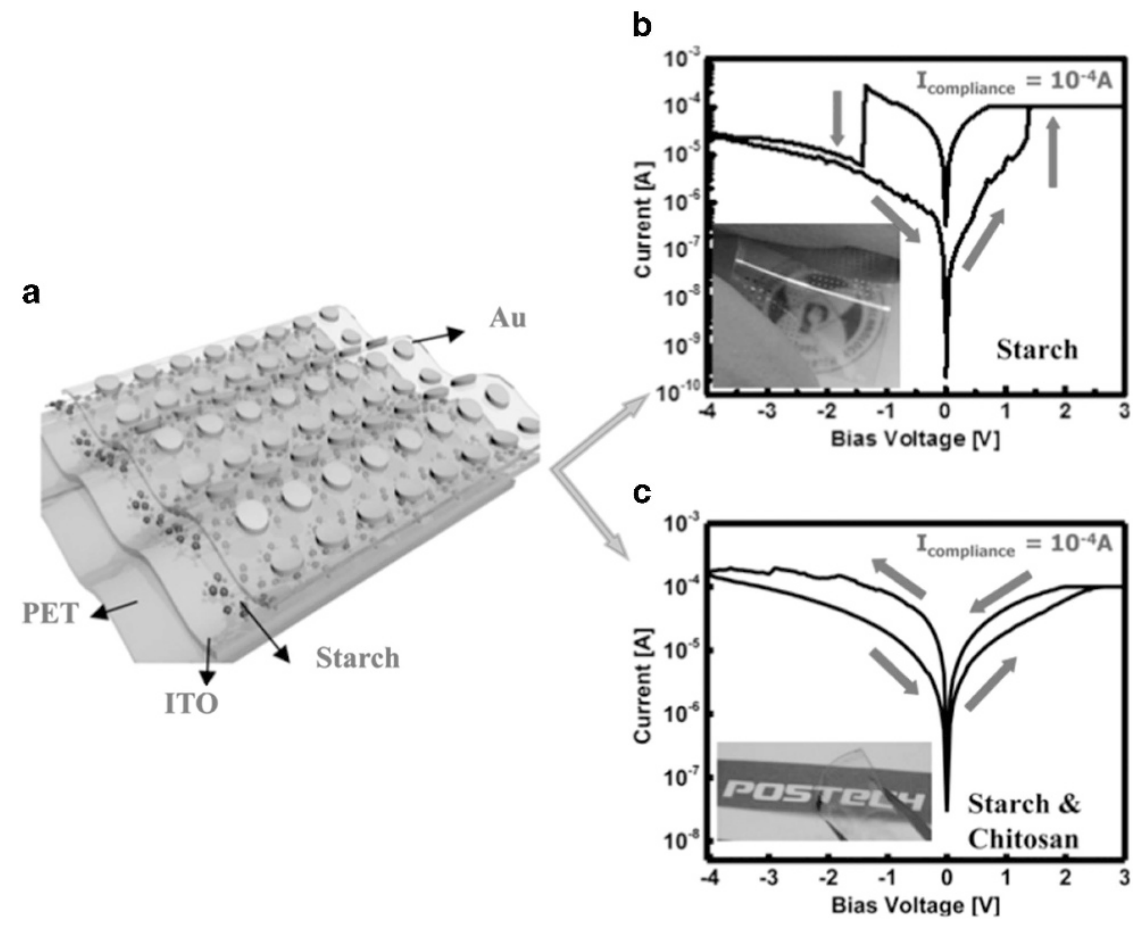

Figure 11 Schematic of fabricated flexible resistive switching devices with an Au/starch or starch-chitosan/indium tin oxide (ITO)/polyethylene terephthalate (PET) configuration and (a) resistive switching characterization of the starch-based or starch-chitosan composite memristors (b, c). A current compliance of $10^{-4} \mathrm{~A}$ was applied to prevent permanent breakdown. Reproduced with permission from ref. 72. Copyright 2016, American Chemical Society. A full color version of this figure is available at Polymer Journal online.

memory because of the exceptional hole transporting property of the carbazole group (Figure 10). In addition, the device showed a high on/off current ratio of $10^{4}$ and could be operated repeatedly. This work was paramount in motivating the application of renewable materials in electronic devices.

In addition to chemical modifications, physical bending with graphene oxide ${ }^{68}$ or metal nanoparticles, such as Ag NPs, ${ }^{69-71}$ could also enhance the application of carbohydrate polymers in electrical devices. Very recently, Hosseini et al. reported flexible and transparent non-volatile memory devices using starch-chitosan composites as the active layers (Figure 11). Specifically, they reported that the memory behavior could be controlled by mixing starch with chitosan in the resistive switching layer. The bipolar switching phenomenon was attributed to the formation and breakdown of carbon-rich filaments. These bio-memory devices also exhibited low operation voltages between -4 and $3 \mathrm{~V}$, with good mechanical reliability (that is, bending cycles up to 1000 with a radius of $5 \mathrm{~mm}$ ) and a retention capability of $10^{4} \mathrm{~s}^{72}$

\section{Proton-transporting layers in organic field-effect transistors}

As opposed to electrons, ions and protons usually dominate the electrical signal transmission in nature. For interfacing with biological systems, it is necessary to recognize the conduction mechanism and understand how to control or monitor the ionic and protonic currents. Zhong and co-workers devised the first biopolymer protonic 


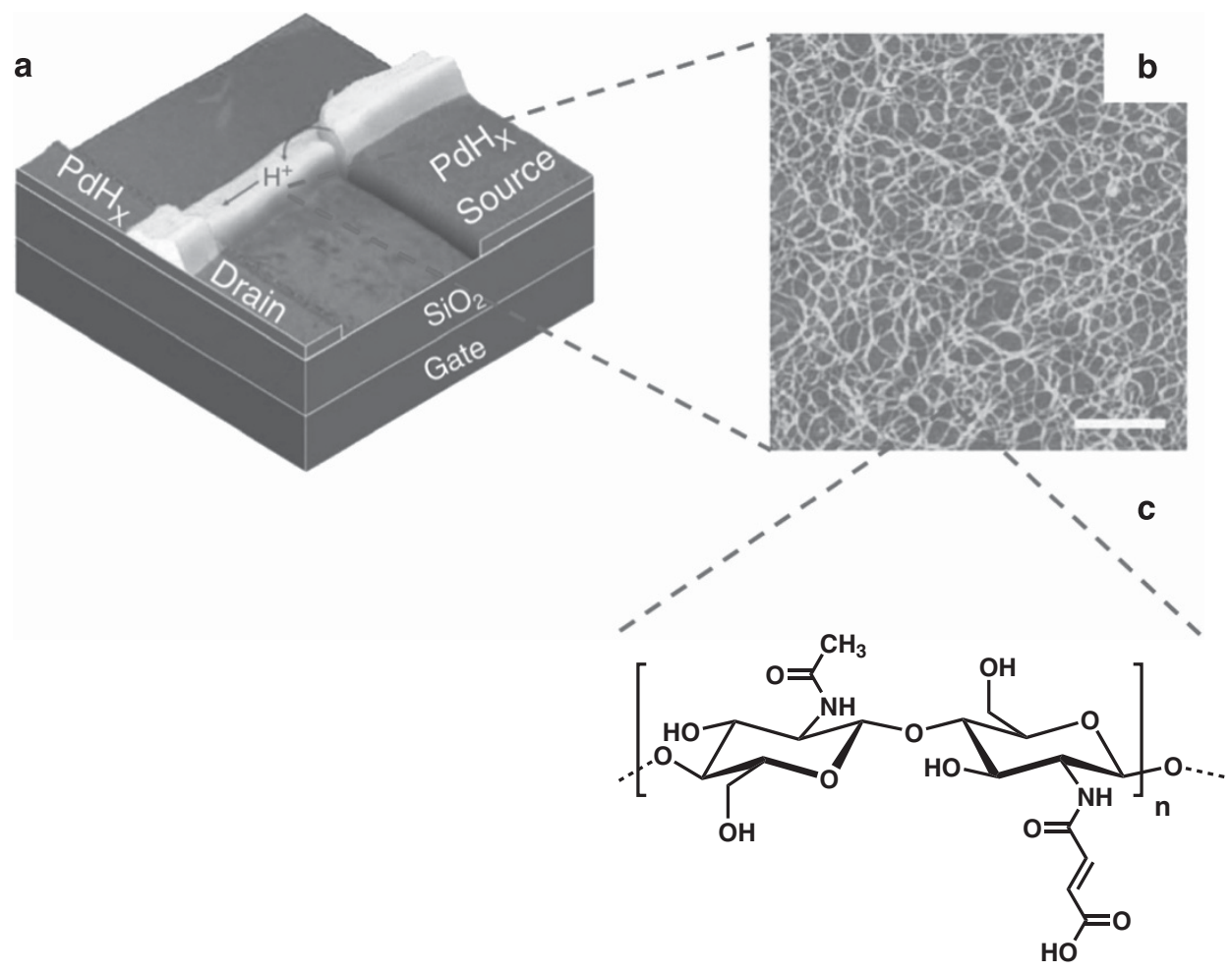

Figure 12 (a) Schematic diagram of protonic field-effect transistors. (b) Atomic force microscopy height image of a maleic-chitosan nanofiber and (c) molecular structure of maleic-chitosan; the degree of substitution $(\mathrm{m} / \mathrm{n})$ is 0.85 for these devices. Reproduced with permission from ref. 73 . Copyright 2011, Nature Publishing Group. A full color version of this figure is available at Polymer Journal online.

a

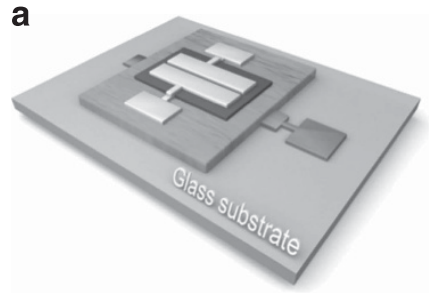

b

TMSC...trimethylsilyl cellulose

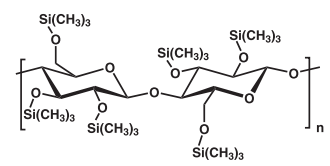

Figure 13 (a) Schematic of the fabricated organic field-effect transistors. (b) Chemical structure of trimethylsilyl cellulose. Reproduced with permission from ref. 78. Copyright 2015, Wiley- $\mathrm{VCH}$. A full color version of this figure is available at Polymer Journal online.

field-effect transistor using a maleic-chitosan hydrogen-bonded network $\left(\mathrm{H}^{+}\right.$-type $)$with proton-transparent palladium hydride contacts (Figure 12). The protonic current switching of the device can be operated by an electrostatic bias applied to the gate electrode. The protons dissociated from the maleic acid groups move along the hydrated maleic-chitosan hydrogen-bonded gel with a proton mobility of $4.9 \times 10^{-3} \mathrm{~cm}^{2} \mathrm{~V}^{-1} \mathrm{~s}^{-1} .^{73}$ In addition, Zhong and co-workers demonstrated that an $\mathrm{OH}^{-}$-type protonic field-effect transistor can also be achieved through acidic or basic doping using a proline-modified chitosan biopolymer as the transporting layer. ${ }^{74}$ Their study introduces a new type of bioelectronic device and highlights the potential of its biomedical applications.

\section{Gate dielectric layers in organic field-effect transistors}

The gate dielectric layer is a crucial component of organic field-effect transistors, which governs the strength of the induced electric field, drain-to-gate current leakage, charge mobility and operating voltage of the device by varying the dielectric capacitance. Inorganic materials with a high dielectric constant, such as $\mathrm{TiO}_{2}, \mathrm{Ta}_{2} \mathrm{O}_{5}, \mathrm{CeO}_{2}, \mathrm{BaTiO}_{3}$ and $\mathrm{BaZrTiO}_{3}$, have been used to increase the capacitance and fabricate low voltage operable devices. Polymeric materials and composites with high dielectric characteristics (for example, poly (acrylic acid), poly(vinylidene fluoride-co-hexafluoropropylene), crosslinked poly(4-vinylphenol) or poly(vinylidene fluoride)/ $\mathrm{BaTiO}_{3}$ composites) have also been used as the gate dielectrics. Recently, several carbohydrate-based dielectric materials have been reported. ${ }^{75-78}$ For example, a pentacene-based organic field-effect transistor with a crosslinked cyanoethyl pullulan dielectric layer was found to operate under a low gate voltage of $-3 \mathrm{~V}$ with a remarkably high mobility of $\sim 8.62 \mathrm{~cm}^{2} \mathrm{~V}^{-1} \mathrm{~s}^{-1}$, an on/off current ratio of $\sim 10^{5}$, and a steep sub-threshold slope of $0.099 \mathrm{~V}$ per dec. ${ }^{75}$ Furthermore, Beaulieu and co-workers added $\mathrm{ZrO}_{2}$ nanoparticles to neat cyanoethyl pullulan as physical crosslinks to eliminate the charge-trapping effect and improve the stability and performance of the P3HT transistor devices. ${ }^{77}$ In addition to functionalized pullulan, Petritz et al. ${ }^{78}$ demonstrated the use of trimethylsilyl cellulose as an organic/inorganic bilayer gate dielectric for organic field-effect transistors and complementary inverters, as shown in Figure 13. Using this bilayer dielectric, the fabricated pentacene- and $\mathrm{C}_{60}$-based transistors can operate under $10 \mathrm{~V}$ with field-effect mobilities of 0.2 and $0.7 \mathrm{~cm}^{2} \mathrm{~V}^{-1} \mathrm{~s}^{-1}$, respectively. Notably, this design operated with 
a

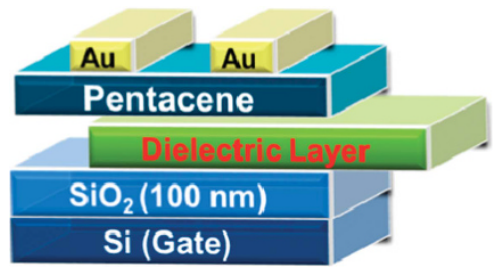

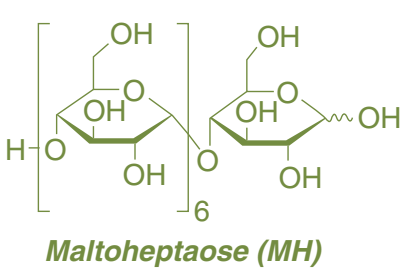

Maltoheptaose $(\mathrm{MH})$ b

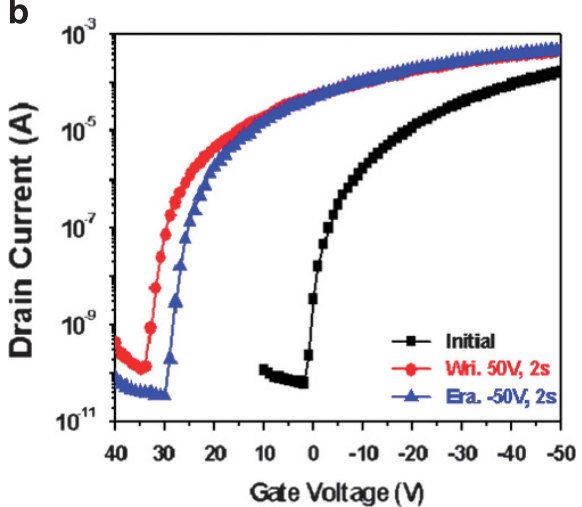

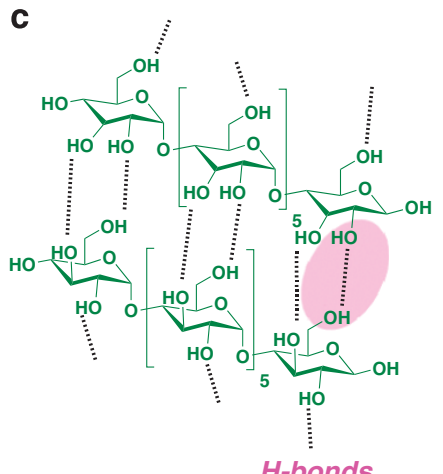

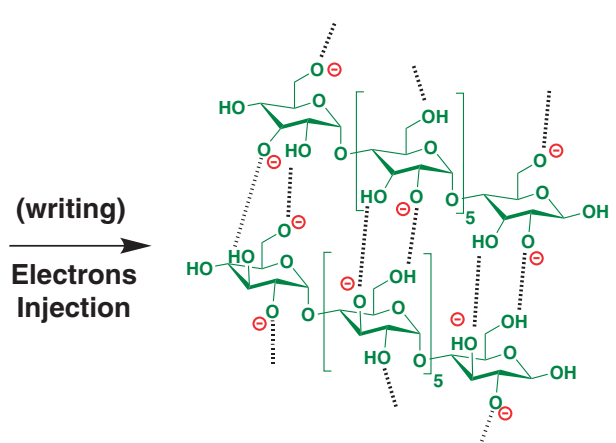

Figure 14 (a) Schematic of the pentacene-based organic field-effect transistor memory device with a maltoheptaose (MH) dielectric layer and its molecular structure. (b) Electrical transfer characteristics of $\mathrm{MH}$-based transistor memory device at $V_{\mathrm{d}}=-30 \mathrm{~V}$. (c) Proposed memory mechanism of irreversible electron trapping within the $\mathrm{MH}$ dielectric. Reproduced with permission from ref. 79. Copyright 2015, Wiley-VCH.

insignificant source-drain hysteresis, implying a low content of shallow traps. From the above results, modified polysaccharide derivatives as dielectric materials demonstrate great promise for further application in integrated circuits as their chemical structures directly affect transistor performance.

Charge-trapping electrets in organic field-effect transistor memory As mentioned, using modified cellulose as the dielectric layer in transistor devices results in a different device performance because the concentration of the induced charge carrier at the dielectric/ semiconductor interface is very different from traditional dielectrics. Chen and co-workers took advantage of pristine functional groups in bio-based materials to store or trap the charge carriers induced at the interface to develop high performance transistor-type memory devices. Furthermore, we demonstrated that an abundance of hydroxyl groups in polysaccharides containing $\alpha$-glucan moieties had multiple charge-storage behaviors according to the contacting interface or the polysaccharide morphology.

As shown in Figure 14, selected polysaccharides, including maltoheptaose, dextran and polysucrose, were inserted into a transistor configuration beneath the semiconducting pentacene layer. After applying a positive gate bias, a large threshold voltage shift was observed in the transfer curve that does not dissipate. These data suggest that the electric-field-induced electrons may have been trapped in the surface of the polysaccharide layer when the external gate bias was applied. Consequently, the device could maintain a non-volatile high-current state with a highly stable retention characteristic, indicating a write-once-read-many-type of behavior. This result suggests that polysaccharides possess an extremely strong chargetrapping capability because the hydroxyl groups may deprotonate once electrons are received from the semiconducting layer, which then generates negatively charged $\mathrm{O}^{-}$ions. The resultant hydroxylate anions potentially enhance hydrogen bonding to improve the electron charge storage in the polysaccharides. ${ }^{79}$

In addition to the structure of the polysaccharide/semiconductor heterojunction, the interaction between the polysaccharide/ semiconductor was reduced using a maltoheptaose- $b$-polystyrene block copolymer (MH- $b$-PS) as the electret in a transistor memory device (Figure 15). Notably, the memory behavior can be converted to flash-type memory because the PS block serves as a tunneling layer and the charge-storage density (that is, the memory window) corresponds to the self-assembly $\mathrm{MH}$ block embedded in the PS matrix. The electron-trapping ability induced by a horizontal-cylinder $\mathrm{MH}$ is stronger than those of either random-sphere or verticalcylinder structures, which can be attributed to the effective contact area of the polarized hydroxyl groups. The electrical performance of the device can be further improved via the supramolecules involving hydrogen bonds between 1-aminopyrene and the hydroxyl groups in the $\mathrm{MH}$ moieties. Overall, this configuration gives an excellent flash memory with a wide memory window $(52.7 \mathrm{~V})$, retention times longer than $10^{4} \mathrm{~s}$, a high on/off ratio of $>10^{5}$ and stable reversibility over 200 cycles. ${ }^{80}$ The above results demonstrate that the judicious use of polysaccharide functional groups can control transistor transfer characteristics for use in high-performance green transistor memory devices.

\section{CONCLUSION AND FUTURE PERSPECTIVES}

We have reviewed representative electronic applications that utilize renewable polymeric materials and have shown great promise in their potential to launch a new generation of green electronics. These bio-based materials can be used as vital components in electrical devices, including substrates and templates or as the active layers in 

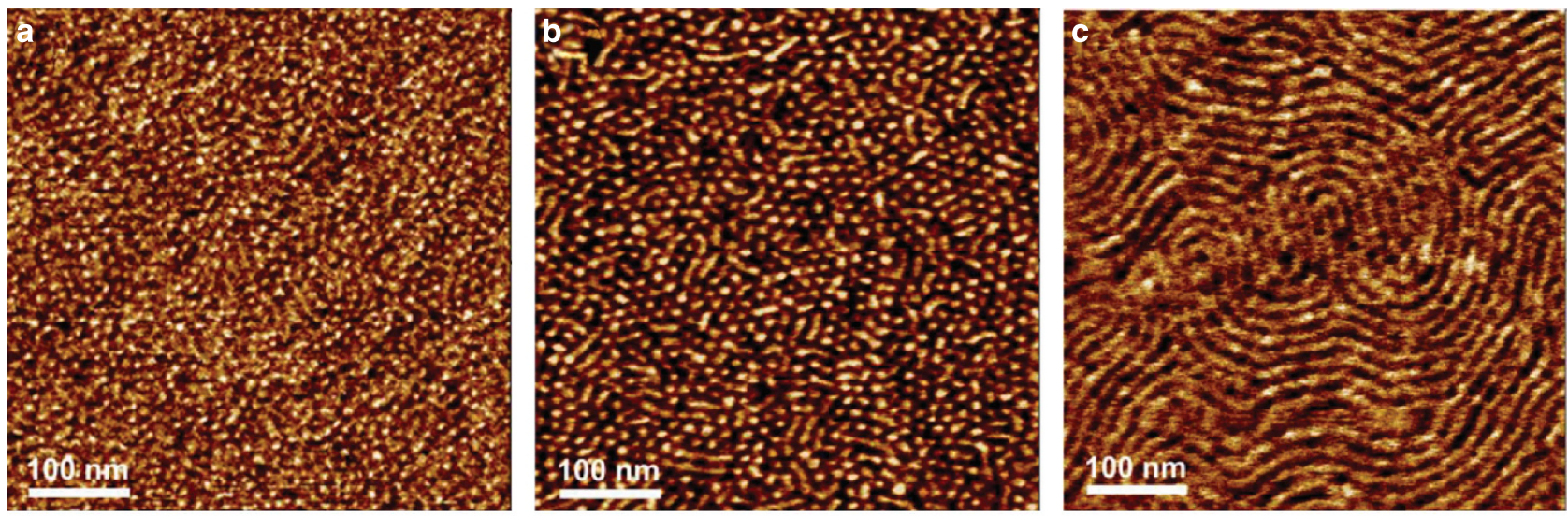

d
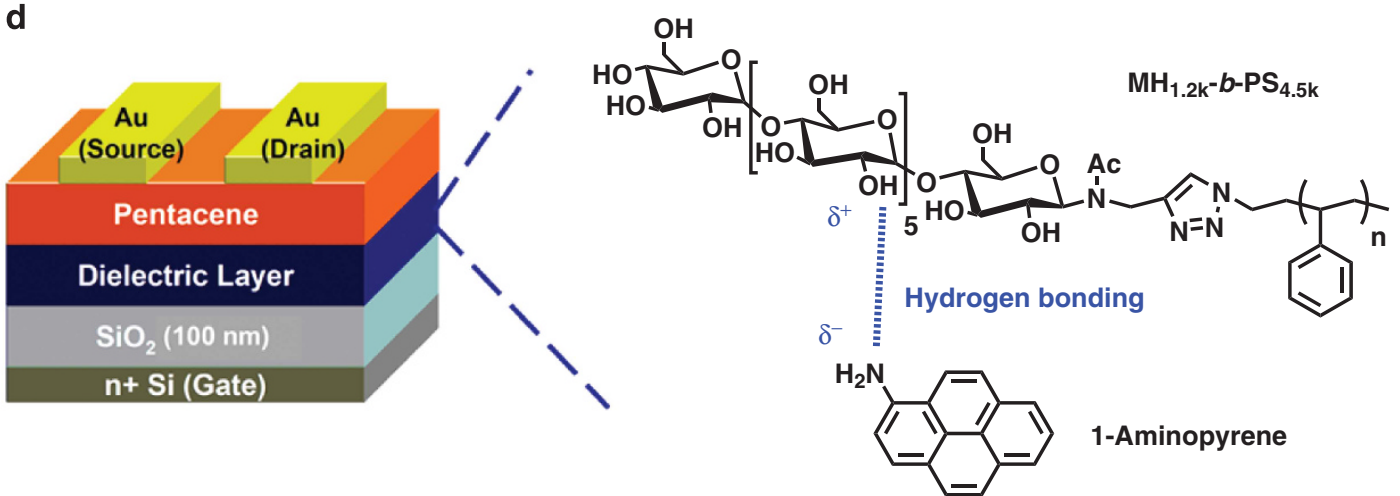

1-Aminopyrene

Figure 15 Atomic force microscopy images of a MH-b-PS diblock copolymer film: (a) spherical morphology; (b) vertical cylinder; (c) horizontal cylinder; and (d) schematic illustration of the pentacene-based organic field-effect transistor memory device and molecular structures of MH- $b$-PS and MH(APy)-b-PS supramolecules. Reproduced with permission from ref. 80. Copyright 2014, Wiley-VCH.

organic electronics. For transistor memory devices in particular, polysaccharides have exhibited comparable or even better performance than the current state-of-the-art metallic nano-floating-gate transistor memory. The results demonstrate that the rational engineering of renewable polymeric materials with desirable electronic properties to interface with electronic devices has the potential to replace inorganic or petroleum-based materials.

However, the direct use of renewable polymeric materials as active electronic components has many issues that must be addressed, which currently limit the extent to which they can be integrated effectively with electronic devices. The first issue concerns solubility because most renewable materials made from biomass are insoluble in organic solvents or can only be dissolved in water, which is problematic for device fabrication. Thermal stability is another issue that must also be addressed. Indeed, cellulose and starch have an abundance of hydroxyl groups that would be damaged at the high temperatures required for device fabrication, leading to structural decomposition of the devices. The third issue that currently limits successful incorporation of renewable polymeric materials with electronic devices is the stability of the renewable materials. Clearly, these materials are biodegradable, and some of them are sensitive to preservation; hence, controlling the degradation rate of the renewable polymeric materials is a key issue that must be addressed for their use in electronics. The final issue of these materials is their inherent lack of electroactivity, which is a crucial feature that the electrical behavior and device performance strongly depend. Nevertheless, despite these issues, renewable materials continue to attract considerable attention because of their worldwide abundance and sustainability and their ability to replace fossil-based materials. Several research directions, including physical or chemical modifications, can be envisioned. For example, hydrolyzing cellulose to oligosaccharides can be utilized to prepare monomers, such as furan derivatives, for developing other polymeric materials. In addition, chemical modifications or exploiting composite technologies may improve the electrical properties of the materials to serve as active layers or dielectrics. Furthermore, carbon-rich backbones are a promising feedstock for the production of highly conductive materials. Finally, the recent development of renewable materials has many exciting applications that await further exploration.

Finally, it is worth mentioning that the overall economics of these materials will likely be enhanced significantly and that the simultaneous waste of non-provision biomass could be used efficiently following the integration of renewable polymeric materials with electronic devices. From biomass raw materials to electronics, this research field has the potential to combine several multidisciplinary sciences, including biotechnology, chemical engineering, polymer science and semiconductor technology, to develop the next generation of green electronics.

\section{CONFLICT OF INTEREST}

The authors declare no conflict of interest.

1 Omer, A. M. Energy, environment and sustainable development. Renew. Sustainable Energy Rev. 12, 2265-2300 (2008).

2 Chu, S. \& Majumdar, A. Opportunities and challenges for a sustainable energy future. Nature 488, 294-303 (2012). 
3 Yamaguchi, S., Tanha, M., Hult, A., Okuda, T., Ohara, H. \& Kobayashi, S. Green polymer chemistry: lipase-catalyzed synthesis of bio-based reactive polyesters employing itaconic anhydride as a renewable monomer. Polym. J. 46, 2-13 (2014).

4 Satoh, K. Controlled/living polymerization of renewable vinyl monomers into bio-based polymers. Polym. J. 47, 527-536 (2015).

$5 \mathrm{Li}, \mathrm{J} ., \mathrm{He}, \mathrm{Y}$. \& Inoue, Y. Study on thermal and mechanical properties of biodegradable blends of poly ( $\varepsilon$-caprolactone) and lignin. Polym. J. 33, 336-343 (2001).

6 Hosoda, N., Tsujimoto, T. \& Uyama, H. Plant oil-based green composite using porous poly (3-hydroxybutyrate). Polym. J. 46, 301-306 (2014).

7 Saravanan, K., Stalin, D. N. \& Jayasuthahar, S. Review of renewable energy resources in clean green environment. IJETEE 1, 54-58 (2013).

8 Nigam, P. S. \& Singh, A. Production of liquid biofuels from renewable resources. Prog. Energy Combust. Sci. 37, 52-68 (2011).

9 Eichhorn, S. J. \& Gandini, A. Materials from renewable resources. MRS Bull. 35, 187-190 (2010)

10 Ebnesajjad, S. in Processing and Applications (ed. Ebnesajjad, S.) (Elsevier, Amsterdam, Netherlands, 2013).

11 Dutta, P. K., Dutta, J. \& Tripathi, V. Chitin and chitosan: chemistry, properties and applications. J. Sci. Ind. Res. 63, 20-31 (2004).

12 Nakai, Y. \& Yoshikawa, M. Cellulose as a membrane material for optical resolution. Polym. J. 47, 334-339 (2015).

13 Sunilkumar, M., Gafoor, A. A., Anas, A., Haseena, A. P. \& Sujith, A. Dielectric properties: a gateway to antibacterial assay - a case study of low-density polyethylene/ chitosan composite films. Polym. J. 46, 422-429 (2014).

14 Huang, X., Zhang, S., Zhang, Y., Zhang, H. \& Yang, X. Sulfonated polyimide/chitosan composite membranes for a vanadium redox flow battery: influence of the sulfonation degree of the sulfonated polyimide. Polym. J. 48, 905-918 (2016).

15 Kumar, M. R., Muzzarelli, R. A., Muzzarelli, C., Sashiwa, H. \& Domb, A. Chitosan chemistry and pharmaceutical perspectives. Chem. Rev. 104, 6017-6084 (2004).

16 Rinaudo, M. Chitin and chitosan: properties and applications. Prog. Polym. Sci. 31, 603-632 (2006)

17 Chiellini, E., Chiellini, F. \& Cinelli, P. in Degradable Polymers_Principles and Application (ed. Scott, G.) (Springer, Berlin, Heidelberg, Germany, 2002).

18 Xu, C., Arancon, R. A. D., Labidi, J. \& Luque, R. Lignin depolymerisation strategies: towards valuable chemicals and fuels. Chem. Soc. Rev. 43, 7485-7500 (2014).

19 Besson, M., Gallezot, P. \& Pinel, C. Conversion of biomass into chemicals over metal catalysts. Chem. Rev. 114, 1827-1870 (2013).

20 Perez, S. \& Bertoft, E. The molecular structures of starch components and their contribution to the architecture of starch granules: a comprehensive review. StarchStarke 62, 389-420 (2010).

21 Damager, I., Engelsen, S. B., Blennow, A., Lindberg Møller, B. \& Motawia, M. S. First principles insight into the $\alpha$-glucan structures of starch: their synthesis, conformation, and hydration. Chem. Rev. 110, 2049-2080 (2010)

22 Lligadas, G., Ronda, J. C., Galià, M. \& Cádiz, V. Renewable polymeric materials from vegetable oils: a perspective. Mater. Today 16, 337-343 (2013).

23 Adekunle, K. F. A review of vegetable oil-based polymers: synthesis and applications. Open J. Polym. Chem. 5, 34 (2015).

24 Isikgor, F. H. \& Becer, C. R. Lignocellulosic biomass: a sustainable platform for the production of bio-based chemicals and polymers. Polym. Chem. 6, 4497-4559 (2015).

25 Gandini, A. in Biocatalysis in Polymer Chemistry (ed. Loos, K.) (Wiley-VCH, Weinheim, Germany, 2011).

26 Belgacem, M. N. \& Gandini, A. in Monomers, Polymers and Composites from Renewable Resources (eds Belgacem, M. N. \& Gandini, A.) (Elsevier, Amsterdam, Netherlands, 2008).

27 Carlsson, A. S., Beilen, J. B, van, Möller, R., Clayton, D. \& Bowles, D. J. Micro-and Macro-Algae: Utility for Industrial Applications: Outputs from the EPOBIO Project, September 2007 (CPL Press, 2007).

28 Priyadarshani, I. \& Rath, B. Commercial and industrial applications of micro algae-a review. J. Algal Biomass UtIn 3, 89-100 (2012).

29 Chen, G.-Q. A microbial polyhydroxyalkanoates (PHA) based bio- and materials industry. Chem. Soc. Rev. 38, 2434-2446 (2009).

30 Koutinas, A. A., Vlysidis, A., Pleissner, D., Kopsahelis, N., Garcia, I. L., Kookos, I. K., Papanikolaou, S., Kwan, T. H. \& Lin, C. S. K. Valorization of industrial waste and by-product streams via fermentation for the production of chemicals and biopolymers. Chem. Soc. Rev. 43, 2587-2627 (2014)

31 Flieger, M., Kantorova, M., Prell, A., Řezanka, T. \& Votruba, J. Biodegradable plastics from renewable sources. Folia Microbiol. 48, 27-44 (2003).

32 Bonartsev, A., Myshkina, V., Nikolaeva, D., Furina, E., Makhina, T., Livshits, V., Boskhomdzhiev, A., Ivanov, E., Iordanskii, A. \& Bonartseva, G. Biosynthesis, biodegradation, and application of poly (3-hydroxybutyrate) and its copolymers-natural polyesters produced by diazotrophic bacteria. Commun. Curr. Res. Educ. Top. Trends Appl. Microbiol. 1, 295-307 (2007).

33 Chen, G.-Q. \& Patel, M. K. Plastics derived from biological sources: present and future: a technical and environmental review. Chem. Rev. 112, 2082-2099 (2011).

34 Flint, K. Biodegradable plastic: its promises and consequences. Dartmouth Undergraduate J. Sci. 12 (2013).

35 Nampoothiri, K. M., Nair, N. R. \& John, R. P. An overview of the recent developments in polylactide (PLA) research. Bioresour. Technol. 101, 8493-8501 (2010).

36 Auras, R. A., Lim, L.-T., Selke, S. E. \& Tsuji, H. in Processing, and Applications (eds Auras, R. A., Lim, L.-T., Selke, S. E. \& Tsuji, H.) (Wiley, Hoboken, NJ, USA, 2010).

37 Rasal, R. M., Janorkar, A. V. \& Hirt, D. E. Poly(lactic acid) modifications. Prog. Polym. Sci. 35, 338-356 (2010).
38 Nguyen, H. D., Kaneko, T., Takaya, N., Fujita, T. \& Ito, T. Fermentation of aromatic lactate monomer and its polymerization to produce highly thermoresistant bioplastics. Polym. J. 48, 81-89 (2015).

39 Fujie, T. Development of free-standing polymer nanosheets for advanced medical and health-care applications. Polym. J. 48, 773-780 (2016).

40 Nogi, M., Iwamoto, S., Nakagaito, A. N. \& Yano, H. Optically transparent nanofiber paper. Adv. Mater. 21, 1595-1598 (2009).

41 Hinestroza, J. P. \& Netravali, A. N. in Cellulose Based Composites: New Green Nanomaterials (eds Hinestroza, J. P. \& Netravali, A. N.) (Wiley-VCH, Weinheim, Germany, 2014).

42 Nogi, M. \& Yano, H. Transparent nanocomposites based on cellulose produced by bacteria offer potential innovation in the electronics device industry. Adv. Mater. 20, 1849-1852 (2008)

43 Fan, X. S., Liu, Z. W., Lu, J. \& Liu, Z. T. Cellulose triacetate optical film preparation from ramie fiber. Ind. Eng. Chem. Res. 48, 6212-6215 (2009).

44 Huang, J., Zhu, H. L., Chen, Y. C., Preston, C., Rohrbach, K., Cumings, J. \& Hu, L. B. Highly transparent and flexible nanopaper transistors. ACS Nano 7, 2106-2113 (2013).

45 Levinson, H. J. Principles of Lithography 3rd edn (SPIE, Bellingham, WA, USA, 2011).

46 Moreau, W. M. Semiconductor Lithography: Principles, Practices, and Materials (Springer, Berlin, Germany, 2012).

47 Fertier, L., Koleilat, H., Stemmelen, M., Giani, O., Joly-Duhamel, C., Lapinte, V. \& Robin, J. J. The use of renewable feedstock in UV-curable materials - a new age for polymers and green chemistry. Prog. Polym. Sci. 38, 932-962 (2013).

48 Gu, X. D., Gunkel, I. \& Russell, T. P. Pattern transfer using block copolymers. Philos. Trans. R. Soc. A Math. Phys. Eng. Sci. 371, 20120306 (2013).

$49 \mathrm{Ji}$, S., Wan, L., Liu, C.-C. \& Nealey, P. F. Directed self-assembly of block copolymers on chemical patterns: a platform for nanofabrication. Prog. Polym. Sci. 54-55, 76-127 (2015)

50 Sinturel, C., Bates, F. S. \& Hillmyer, M. A. High $\chi$-low N block polymers: how far can we go? ACS Macro Lett. 4, 1044-1050 (2015).

51 Cushen, J. D., Otsuka, I., Bates, C. M., Halila, S., Fort, S., Rochas, C., Easley, J. A., Rausch, E. L., Thio, A., Borsali, R., Willson, C. G. \& Ellison, C. J. Oligosaccharide/ silicon-containing block copolymers with $5 \mathrm{~nm}$ features for lithographic applications. ACS Nano 6, 3424-3433 (2012).

52 Cushen, J. D., Bates, C. M., Rausch, E. L., Dean, L. M., Zhou, S. X., Willson, C. G. \& Ellison, C. J. Thin film self-assembly of poly(trimethylsilylstyrene- $b$-D, L-lactide) with sub-10 nm domains. Macromolecules 45, 8722-8728 (2012).

53 Pitet, L. M., Wuister, S. F., Peeters, E., Kramer, E. J., Hawker, C. J. \& Meijer, E. W. Well-organized dense arrays of nanodomains in thin films of poly(dimethylsiloxane)- $b$ poly(lactide) diblock copolymers. Macromolecules 46, 8289-8295 (2013).

54 Cushen, J. D., Wan, L., Pandav, G., Mitra, I., Stein, G. E., Ganesan, V., Ruiz, R., Willson, C. G. \& Ellison, C. J. Ordering poly(trimethylsilyl styrene-block-(D),(L)-lactide) block copolymers in thin films by solvent annealing using a mixture of domain-selective solvents. J. Polym. Sci. B: Polym. Phys. 52, 36-45 (2014).

55 Minehara, H., Pitet, L. M., Kim, S., Zha, R. H., Meijer, E. W. \& Hawker, C. J. Branched block copolymers for tuning of morphology and feature size in thin film nanolithography. Macromolecules 49, 2318-2326 (2016).

56 Botiz, I. \& Darling, S. B. Self-assembly of poly (3-hexylthiophene)-block-polylactide block copolymer and subsequent incorporation of electron acceptor material. Macromolecules 42, 8211-8217 (2009).

$57 \mathrm{Li}, \mathrm{X}$., Zhu, J. \& Wei, B. Hybrid nanostructures of metal/two-dimensional nanomaterials for plasmon-enhanced applications. Chem. Soc. Rev. 45, 3145-3187 (2016).

58 Zhang, Y. C., Chu, W. D., Foroushani, A. D., Wang, H. B., Li, D., Liu, J. Q., Barrow, C. J., Wang, X. \& Yang, W. R. New gold nanostructures for sensor applications: a review. Materials 7, 5169-5201 (2014).

59 Hu, M., Chen, J. Y., Li, Z. Y., Au, L., Hartland, G. V., Li, X. D., Marquez, M. \& Xia, Y. N. Gold nanostructures: engineering their plasmonic properties for biomedical applications. Chem. Soc. Rev. 35, 1084-1094 (2006).

60 Hsueh, H. Y., Chen, H. Y., Hung, Y. C., Ling, Y. C., Gwo, S. \& Ho, R. M. Well-defined multibranched gold with surface plasmon resonance in near-infrared region from seeding growth approach using gyroid block copolymer template. Adv. Mater. 25, 1780-1786 (2013).

61 Dolan, J. A., Wilts, B. D., Vignolini, S., Baumberg, J. J., Steiner, U. \& Wilkinson, T. D. Optical properties of gyroid structured materials: from photonic crystals to metamaterials. Adv. Opt. Mater. 3, 12-32 (2015).

62 Chen, Y. A., Star, A. \& Vidal, S. Sweet carbon nanostructures: carbohydrate conjugates with carbon nanotubes and graphene and their applications. Chem. Soc. Rev. 42, 4532-4542 (2013)

63 Gorityala, B. K., Ma, J. M., Wang, X., Chen, P. \& Liu, X. W. Carbohydrate functionalized carbon nanotubes and their applications. Chem. Soc. Rev. 39, 2925-2934 (2010).

64 Kharissova, O. V., Kharisov, B. I. \& Ortiz, E. G. D. Dispersion of carbon nanotubes in water and non-aqueous solvents. RSC Adv. 3, 24812-24852 (2013).

65 Sudibya, H. G., Ma, J. M., Dong, X. C., Ng, S., Li, L. J., Liu, X. W. \& Chen, P. Interfacing Glycosylated carbon-nanotube-network devices with living cells to detect dynamic secretion of biomolecules. Angew. Chem. Int. Ed. 48, 2723-2726 (2009).

66 Karakawa, M., Chikamatsu, M., Vakamoto, C., Maeda, Y., Kubota, S. \& Yase, K. Organic light-emitting diode application of fluorescent cellulose as a natural polymer. Macromol. Chem. Phys. 208, 2000-2006 (2007).

67 Karakawa, M., Chikamatsu, M., Yoshida, Y., Azumi, R., Yase, K. \& Nakamoto, C. Organic memory device based on carbazole-substituted cellulose. Macromol. Rapid Commun. 28, 1479-1484 (2007). 
68 Valentini, L., Cardinali, M., Fortunati, E. \& Kenny, J. M. Nonvolatile memory behavior of nanocrystalline cellulose/graphene oxide composite films. Appl. Phys. Lett. 105, 153111 (2014).

69 Nagashima, K., Koga, H., Celano, U., Zhuge, F., Kanai, M., Rahong, S., Meng, G., He, Y., De Boeck, J., Jurczak, M., Vandervorst, W., Kitaoka, T., Nogi, M. \& Yanagida, T. Cellulose nanofiber paper as an ultra flexible nonvolatile memory. Sci. Rep. 4, 5532 (2014).

70 Hosseini, N. R. \& Lee, J. S. Biocompatible and flexible chitosan-based resistive switching memory with magnesium electrodes. Adv. Funct. Mater. 25, 5586-5592 (2015).

71 Hosseini, N. R. \& Lee, J. S. Resistive switching memory based on bioinspired natural solid polymer electrolytes. ACS Nano 9, 419-426 (2015).

72 Raeis-Hosseini, N. \& Lee, J. S. Controlling the resistive switching behavior in starch-based flexible biomemristors. ACS Appl. Mater. Interfaces 8, 7326-7332 (2016).

73 Zhong, C., Deng, Y. X., Roudsari, A. F., Kapetanovic, A., Anantram, M. P. \& Rolandi, M. A polysaccharide bioprotonic field-effect transistor. Nat. Commun. 2, 476 (2011)

74 Deng, Y. X., Josberger, E., Jin, J. H., Rousdari, A. F., Helms, B. A., Zhong, C., Anantram, M. P. \& Rolandi, M. $\mathrm{H}^{+}$-type and $\mathrm{OH}^{-}$-type biological protonic semiconductors and complementary devices. Sci. Rep. 3, 2481 (2013).
75 Xu, W., Guo, C. \& Rhee, S.-W. 'Knitting up' the inter-dipole gaps in dielectric surfaces: an efficient route for high performance organic field-effect transistors. J. Mater. Chem. 22, 6597-6602 (2012).

$76 \mathrm{Xu}$, W., Guo, C. \& Rhee, S.-W. High performance organic field-effect transistors using cyanoethyl pullulan (CEP) high-k polymer cross-linked with trimethylolpropane triglycidyl ether (TTE) at low temperatures. J. Mater. Chem. C 1, 3955-3960 (2013).

77 Beaulieu, M. R., Baral, J. K., Hendricks, N. R., Tang, Y., Briseño, A. L. \& Watkins, J. J. Solution processable high dielectric constant nanocomposites based on $\mathrm{ZrO}_{2}$ nanoparticles for flexible organic transistors. ACS Appl. Mater. Interfaces 5, 13096-13103 (2013).

78 Petritz, A., Wolfberger, A., Fian, A., Griesser, T., Irimia-Vladu, M. \& Stadlober, B. Cellulose-derivative-based gate dielectric for high-performance organic complementary inverters. Adv. Mater. 27, 7645-7656 (2015).

79 Chiu, Y. C., Sun, H. S., Lee, W. Y., Halila, S., Borsali, R. \& Chen, W. C. Oligosaccharide carbohydrate dielectrics toward high-performance non-volatile transistor memory devices. Adv. Mater. 27, 6257-6264 (2015).

80 Chiu, Y. C., Otsuka, I., Halila, S., Borsali, R. \& Chen, W. C. High-performance nonvolatile transistor memories of pentacence using the green electrets of sugar-based block copolymers and their supramolecules. Adv. Funct. Mater. 24, 4240-4249 (2014).

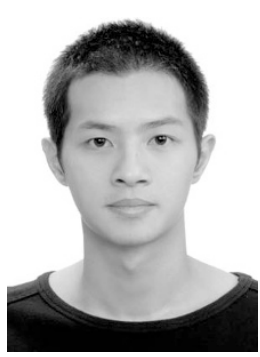

Han-Sheng Sun received his BS degree in Chemical and Materials Engineering (2007) from Tamkang University and MS degree in Polymer Science and Engineering (2009) from National Taiwan University. He joined the group of Prof. Wen-Chang Chen as a $\mathrm{PhD}$ student in 2011. His research interests include synthesis, morphology and memory applications of green block copolymers.
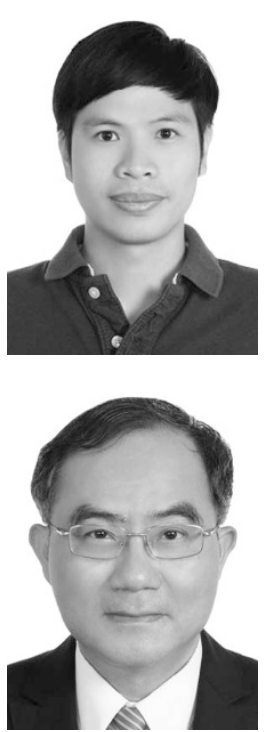

Yu-Cheng Chiu received his PhD degrees under the supervision from Prof. Wen-Chang Chen in Chemical Engineering at National Taiwan University in 2012. After carrying out postdoctoral research in Prof. Chen's group till October 2014, he worked in Prof. Zhenan Bao's group at Stanford University as a Post-doctoral Fellow from 2014 to 2016. Currently, he is an assistant professor in the Department of Chemical Engineering and Materials Science, Yuan Ze University, Taiwan. His research interest focuses on the morphology of conjugated polymers and their application in soft and stretchable electronics.

Wen-Chang Chen is an Associate Dean of College of Engineering, Director of Center for Strategic Materials Alliance for Research and Technology, Distinguished Professor in Department of Chemical Engineering and Institute of Polymer Science and Engineering at National Taiwan University. He received a PhD degree in Chemical Engineering department from University of Rochester in 1993, and then served at a research scientist at Industrial Technology Research Institute of Taiwan from 1993 to 1996. He joined National Taiwan University as an Associate Professor in 1996 and promoted to full professor in 2000. His current research activities include electronic and optoelectronic polymers, block copolymers, and hybrid materials. He has co-authored 316 refereed articles and 42 issued patents. 